\title{
Criminology, Criminal Justice, Law \& Society
}

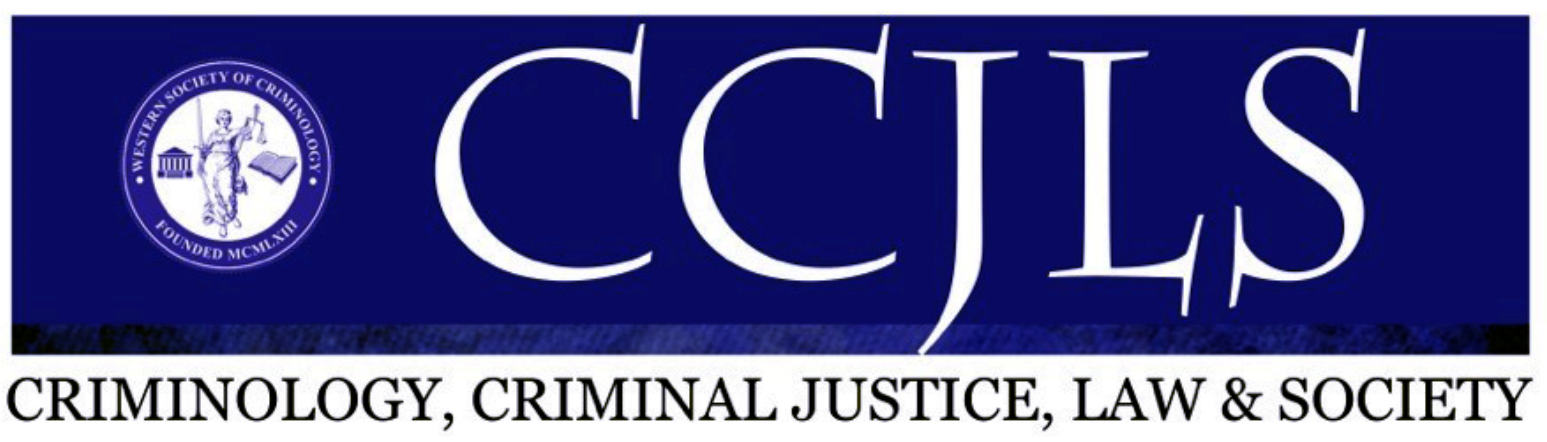

E-ISSN 2332-886X

Available online at

https://scholasticahq.com/criminology-criminal-justice-law-society/

\section{Perceptions of Image-Based Sexual Abuse Among the American Public}

\author{
Corey Call \\ Longwood University
}

\section{ABSTRACT AND ARTICLE INFORMATION}

Image-based sexual abuse (IBSA) involves the sharing or distribution of erotic material without the consent of the subject in the material. A common scenario of IBSA revolves around an individual sharing erotic material of their former intimate partner following the dissolution of the relationship in order to humiliate or harass that former partner for a perceived wrongdoing. This scenario has caused IBSA to be referred to as "revenge porn" in the past, but that phrase does not capture the full breadth of IBSA behaviors and motivations. IBSA is a relatively new phenomenon, having emerged in the last decade, and few studies have examined public perceptions of the activity. In the present study, the attitudes of a national sample $(n=$ 1,023) of Americans were examined on IBSA-related issues. Results of this study showed that the general public largely disapproves of IBSA and supports its criminalization; however, the public also attributes blame to the victims of IBSA. Several factors influence these perceptions including sex, race, age, parental status, political orientation, and sexting history.

Article History:

Received May 13, 2021

Received in revised form September 19, 2021

Accepted September 21, 2021

\section{Keywords:}

image-based sexual abuse, revenge pornography, sexting, victim blaming

(C) 2021 Criminology, Criminal Justice, Law \& Society and The Western Society of Criminology Hosting by Scholastica. All rights reserved.

Corresponding author: Corey Call, PhD, Department of Sociology, Anthropology, and Criminal Justice Studies, Longwood University, 201 High Street, Farmville, VA, 23909, USA.

Email: callcp@longwood.edu 
The sending of self-produced sexually explicit material to others, or "sexting," has become commonplace. Studies in Australia, the United Kingdom (U.K.), and the United States (U.S.) indicate that between $41 \%$ and $61 \%$ of young adults have sent self-produced sexually explicit material to someone else at least once (Branch et al., 2017; Henry et al., 2017; Scott \& Gavin, 2018). When self-produced sexually explicit material is purposefully sent to one party and then the receiving party shares that material with others without the consent of the creator of the material, sexting transforms into image-based sexual abuse (IBSA).

Prevalence rates of IBSA victimization range from $4 \%$ to $12.8 \%$ among samples of U.S. adults (Branch et al., 2017; Eaton et al., 2017; Lenhart et al., 2016; Ruvalcaba \& Eaton, 2020). Victims of IBSA have faced an uphill battle in pursuing justice. There is no federal law pertaining to IBSA. In 2004, New Jersey became the first state to enact IBSA legislation by making it a felony to distribute another person's sexually explicit photos without their consent (Beyens \& Lievens, 2016). IBSA legislation has been met with opposition as critics claim that sharing images or videos, even without the consent of the subject, is an exercise of free speech (Barmore, 2015). Thus, IBSA legislation infringes on First Amendment protections. For instance, in 2019, a Minnesota Court of Appeals found the state's IBSA law too broad and in violation of a defendant's constitutional rights before the Minnesota Supreme Court upheld the legislation the following year (Xiong, 2020). Despite challenges, all but two states (Massachusetts and South Carolina,) presently have laws that address IBSA. How IBSA is defined and the possible punishments for IBSA perpetrators, however, vary across state statutes (Cyber Civil Rights Initiative, 2021).

IBSA has emerged as a prominent technology-facilitated crime and evolving criminal justice policy issue. As IBSA is a relatively new phenomenon, empirical research on the subject is limited. The purpose of the present study is to contribute to the literature on IBSA by exploring the experiences of U.S. residents with IBSA, gauging public perceptions of IBSA, and examining factors that influence those perceptions.

\section{Literature Review}

\section{IBSA and Revenge Pornography}

IBSA has been referred to as "revenge pornography" with the implication being that those sharing sexually explicit material without consent are doing so with the intent to harm or humiliate the creator of the material following a perceived insult.
For instance, during the course of a relationship, an individual creates and sends sexually explicit photos of themselves to their partner with the understanding that the photos are to be kept private. Following the dissolution of the relationship, however, the partner who received the sexually explicit photos publicly posts that material on the Internet. In 2019, Katie Hill resigned from her position as a member of the U.S. House of Representatives after admitting to having an inappropriate romantic relationship with a congressional staffer. The political blog RedState published the initial allegations against Hill along with several nude photos that Hill alleged were released without her consent by her husband to damage her reputation during divorce proceedings (Lee, 2019).

While IBSA may be motivated by revenge in some cases, the term "revenge pornography" is limiting in that it does not capture the full range of motivations for IBSA. Perpetrators of IBSA may be motivated by a variety of factors including sexual gratification, misogyny, notoriety, financial gain, or entertainment (Beyens \& Lievens, 2016; Kamal \& Newman, 2016). Referring to IBSA as revenge pornography also implies a direct relationship between perpetrator and victim culminating in the perpetrator desiring retribution. Perpetrators of IBSA, however, may have no actual connection to their victim. IBSA may involve the hacking of private devices and theft of self-made sexually explicit material. In 2014, hundreds of intimate photos were stolen from the private iCloud accounts of various female celebrities and posted to anonymous online message boards before quickly spreading across the Internet (Grant, 2014). It is also important to note that victims of IBSA may not have even knowingly created the sexually explicit material that was shared, but instead were covertly recorded. In 2019, PornHub, the world's largest pornography website, removed secretly recorded videos depicting female college athletes undressing and showering in a locker room that were allegedly recorded several years prior (Bogage, 2019). Therefore, referring to IBSA as revenge pornography is an oversimplification of a complex behavior involving a variety of motivations and dynamics between perpetrators and victims.

\section{IBSA Perpetration}

While there is little research examining the characteristics of IBSA perpetrators, the available studies from Australia and the U.S. do reveal some common traits among IBSA perpetrators. IBSA perpetrators are more likely to be male than female (Powell et al., 2019; Ruvalcaba \& Eaton, 2020). Also, IBSA perpetration appears to be influenced by sexual orientation. For instance, Powell and colleagues (2019) found higher rates of self-reported distribution 
of non-consensual sexual images among lesbian, gay, or bisexual participants $(13.7 \%)$ compared to heterosexual participants $(5.4 \%)$. Ruvalcaba and Eaton (2020) also found higher rates of self-reported IBSA perpetration among homosexual men (10.8\%) compared to heterosexual men $(6.4 \%)$, but did not find a significant difference in self-reported IBSA perpetration between lesbian women and heterosexual women. Additionally, IBSA perpetrators are most likely to target either a current romantic partner, former romantic partner, or friend for victimization (Powell et al., 2019; Ruvalcaba \& Eaton, 2020).

Some websites that host non-consensual material allow the user uploading the content to add text along with the material. In an analysis of 108 nonconsensual images that contained accompanying text across seven websites, Uhl and colleagues (2018) found that the most common themes included by IBSA perpetrators are insulting references to the subject of the material $(26.9 \%)$, references to the subject of the material being a former partner of the individual uploading the material $(25.4 \%)$, and references to specific body parts of the subject of the material $(21.6 \%)$.

In a more direct examination of revengemotivated IBSA perpetration, Hall and Hearn (2017) analyzed the text accompanying user submissions of non-consensual material on one website where a revenge motive could be discerned. Common reasons for users seeking revenge against former partners by posting non-consensual material of them included claims of being controlled by their former partner during their relationship, claims of sexual infidelity or promiscuity by their former partner, and being denied access to their children by their former partner since the dissolution of their relationship.

\section{IBSA Victimization}

Whereas the majority of IBSA perpetrators appear to be male (Eaton et al., 2017; Powell et al., 2019; Ruvalcaba \& Eaton, 2020), IBSA victims appear to be overwhelmingly female (Branch et al., 2017; Eaton et al., 2017; Ruvalcaba \& Eaton, 2020; Uhl et al., 2018). For instance, Uhl and colleagues (2018) discovered that photographs of women comprised $91.8 \%$ of the material across seven different IBSA websites despite six of those seven websites allowing for submissions of material featuring men and women. It should be noted, however, that not every scholarly study expresses that women are the predominate victims of IBSA. In a survey of cyber dating abuse among university students in Spain, Borrajo and colleagues (2015) found that a significantly higher percentage of men $(8.3 \%)$ reported that their female significant others had shared intimate images of them without consent compared to women $(3.1 \%)$ and their male significant others.

Gender is not the only significant factor in IBSA victimization. Branch and colleagues (2017) examined differences between college students who participated in sexting, but did not experience IBSA and college students who had participated in sexting and then had the material they sent shared with other parties without their consent. Compared to those who had participated in sexting, but did not experience IBSA, IBSA victims were more likely to be non-white, more likely to be in a relationship, more impulsive, hold more positive attitudes toward sexting, and less likely to have engaged in IBSA perpetration themselves.

When sexually explicit material is uploaded to the Internet, it may be impossible to completely remove the material as it spreads around the globe from user to user and website to website. Not only are the private images of victims on display, but this material may be accompanied by personal information about the victim including their full names, area of residence, and links to social media profiles (Stroud, 2014). Through IBSA, victims have their privacy invaded, which then enables a range of other consequences. The effects of IBSA on the mental health of victims can be devastating. Victims of IBSA may experience powerlessness, shame, humiliation, anxiety, depression, loss of self-esteem, eating disorders, and other psychological issues (Bates, 2017; Kamal \& Newman, 2016; Uhl et al., 2018). Bates (2017) equated the overall mental health consequences stemming from IBSA victimization to those experienced by rape survivors. Beyond the impact on their mental health, victims can suffer other lifealtering effects of IBSA including loss of educational opportunities, termination of employment, and difficulty gaining future employment as the sexually explicit material of the victim is discovered online during interview processes and background checks (Bates, 2017; Kamal \& Newman, 2016). To manage these effects, some IBSA victims have developed negative coping strategies including withdrawing from society and chemical dependence while others have attempted suicide (Bates, 2017; Kamal \& Newman, 2016).

\section{Public Perceptions of IBSA}

Empirical research examining public perceptions of IBSA has focused primarily on victim blaming attitudes. As IBSA victimization may involve the victim creating and initially sharing the sexually explicit material, IBSA victims are sometimes attributed blame for their victimization. For instance, when the nude photos of Representative Katie Hill emerged online without her consent, the Speaker of the 
House of Representatives, Nancy Pelosi, commented that young candidates should be warned to be careful of photos that they transmit (Adegoke, 2019). The argument made is that if the victim had never created the explicit material to begin with or had at least not shared it initially, then it could never have been shared without their consent. Varying levels of victim blame for IBSA victims have been recorded. In a survey of U.S. college freshman, only $18 \%$ of respondents agreed that a person who consensually shares a sexually explicit photo of themselves deserves to then have that photo shared with other people (Branch et al., 2017). Higher levels of victim blaming were found in a survey of Australians, where $65 \%$ of respondents agreed that a person who sends an intimate image to another person is at least partially responsible if that image is then shared with others (Henry et al., 2017).

Four studies were identified that examined what factors influence attributing blame to victims of IBSA. All four studies utilized IBSA vignettes or scenarios to evaluate victim blaming attitudes across survey participants. In the most recent study identified, Mckinlay and Lavis (2020) established a relationship between the content of the material shared by the perpetrator and victim blaming attitudes. Namely, when the shared content featured higher levels of nudity, (such as exposed breasts) the victims were attributed greater blame than when the shared content featured lower levels of nudity (such as the victim in lingerie). Starr and Lavis (2018) discovered that the length of time the perpetrator and victim had been in a relationship prior to the victim sharing self-produced sexually explicit material with the perpetrator impacted the degree to which the victim was blamed for the future IBSA. Specifically, when the victim shared self-produced sexually explicit material earlier in the relationship, the victim was blamed more when the perpetrator shared that material without consent than when the victim shared self-produced sexually explicit material later in the relationship and it was then shared without consent.

This finding by Starr and Lavis (2018) is in opposition to findings by Bothamley and Tulley (2018), who observed that the length of the relationship had no impact on blame attributed to the victim. Further, Bothamley and Tulley (2018) also found no relationship between how the relationship ended (amicably or as a result of unfaithfulness) and blame attributed to the victim. A significant relationship was found between participant gender and blame attributed to the victim. While, overall, the participants attributed low levels of blame to the victims across IBSA scenarios, male participants were significantly more likely to attribute blame to IBSA victims than female participants (Bothamley \& Tulley, 2018).
Scott and Gavin (2018), however, did not uncover a significant relationship between participant gender and victim blaming. The researchers did find a relationship between participant sexting experience and victim blaming. Specifically, participants who had not participated in sexting were more likely to blame IBSA victims than participants who had participated in sexting in the past (Scott \& Gavin, 2018).

To a lesser extent, research examining public perceptions of IBSA has also focused on the acceptability of IBSA perpetration and attitudes toward criminalization of IBSA. When asked if someone receiving a nude or semi-nude photo of a friend should share that photo with others, Branch and colleagues (2017), found that U.S. college students overwhelmingly agreed $(92.3 \%)$ that the receiver should not share the image. While that speaks more to the morality of the behavior, the respondents did recognize potential legal consequences of IBSA perpetration with over $77 \%$ of respondents agreeing that they could get into trouble if they were to share a sexually explicit photo of someone without their consent. In a survey of U.S. residents, Lageson and colleagues ( (2019) found that over 94\% of respondents support the criminalization of posting sexually explicit material of someone without their permission; however, support for criminalization decreased to $76.3 \%$ if the victim originally created the sexually explicit material that was shared. While not specifically focusing on victim blaming, this finding by Lageson and colleagues (2019) does further emphasize how victims of IBSA are blamed for their own victimization and how these perceptions affect policy support.

\section{The Current Study}

IBSA is a relatively new phenomenon, and there is little empirical research examining public perceptions toward IBSA. A recent study of the prevalence of IBSA victimization revealed that 1 out of 12 U.S. residents has been a victim of IBSA (Ruvalcaba \& Eaton, 2020). Yet, as of this writing, only two studies (Branch et al., 2018; Lageson et al., 2019) were identified that surveyed U.S. residents on their attitudes toward IBSA. The aim of the present study is to gain a better understanding of how IBSA is perceived among the American public. The current study will first examine the prevalence of IBSA perpetration and victimization among a sample of U.S. residents. The study will then explore the perceptions of the sample toward various IBSA issues, including the appropriateness of nonconsensual sharing of sexually explicit material, criminality of IBSA in two forms, and responsibility of the victim in IBSA. Lastly, the present study will consider the role of 
multiple factors that may influence the perceptions of the sample toward IBSA.

\section{Method}

\section{Sample}

A total of 1,023 respondents participated in the study. The demographic characteristics of the sample are detailed in Table 1. The sample was predominantly female $(56.5 \%)$ and white $(73.8 \%)$. Participants were most likely to be between 30 and 39 years old $(34.4 \%)$ with slightly over one-quarter (26.1\%) of the participants being between 18 and 29 years old. The sample was well-educated with $66.3 \%$ of the respondents having some form of a college degree. Over one-third (39.6\%) reported a yearly household income of at least $\$ 60,000$. The respondents were most likely to be married $(45.9 \%)$ and almost equally likely to be a parent (51.2\%) or not be a parent $(48.8 \%)$. The sample featured respondents from every U.S. state, except for Wyoming, but respondents were most likely to be located in the South (39.4\%). Politically, the respondents were most likely to consider themselves to be liberal or very liberal $(44.6 \%)$.

Table 1: Demographics of Sample

\begin{tabular}{|c|c|}
\hline & $\%(N)$ \\
\hline \multicolumn{2}{|l|}{$\operatorname{Sex}(n=1,019)$} \\
\hline Female & $56.5(576)$ \\
\hline Male & $43.5(443)$ \\
\hline \multicolumn{2}{|l|}{ Race $(n=1,021)$} \\
\hline White & $73.8(753)$ \\
\hline African American & $8.9(91)$ \\
\hline American Indian or Alaskan Native & $1.0(10)$ \\
\hline Asian or Pacific Islander & $7.9(81)$ \\
\hline Hispanic or Latino & $6.2(63)$ \\
\hline Other & $2.3(23)$ \\
\hline \multicolumn{2}{|l|}{ Age $(n=1,023) ; M=38.7 ; S D-12.6$} \\
\hline $18-29$ & $26.1(267)$ \\
\hline $30-39$ & $34.4(352)$ \\
\hline $40-49$ & $18.9(193)$ \\
\hline $50-59$ & $12.6(129)$ \\
\hline $60-69$ & $6.5(66)$ \\
\hline $70+$ & $1.6(16)$ \\
\hline
\end{tabular}

\begin{tabular}{|c|c|}
\hline \multicolumn{2}{|l|}{ Education $(n=1,018)$} \\
\hline Less than high school & $1.0(10)$ \\
\hline $\begin{array}{l}\text { High school diploma or equivalent } \\
\text { (GED) }\end{array}$ & $8.6(88)$ \\
\hline Some college, but no degree & $24.1(245)$ \\
\hline Associate degree & $12.3(125)$ \\
\hline Bachelor's degree & $37.8(385)$ \\
\hline Graduate or professional degree & $16.2(165)$ \\
\hline \multicolumn{2}{|l|}{ Income $(n=1,019)$} \\
\hline Less than $\$ 10,000$ & $4.6(47)$ \\
\hline$\$ 10,001-\$ 19,999$ & $9.1(93)$ \\
\hline$\$ 20,000-\$ 39,999$ & $23.1(235)$ \\
\hline$\$ 40,000-\$ 59,999$ & $23.6(240)$ \\
\hline$\$ 60,000-\$ 79,999$ & $26.2(267)$ \\
\hline Greater than $\$ 80,000$ & $13.4(137)$ \\
\hline \multicolumn{2}{|l|}{ Marital Status $(n=1,021)$} \\
\hline Never married & $40.0(408)$ \\
\hline Married & $45.9(469)$ \\
\hline Separated & $2.0(20)$ \\
\hline Divorced & $10.0(102)$ \\
\hline Widowed & $2.2(22)$ \\
\hline \multicolumn{2}{|l|}{ Have Children $(n=1,010)$} \\
\hline No & $48.8(293)$ \\
\hline Yes & $51.2(517)$ \\
\hline \multicolumn{2}{|l|}{ Region $(n=1,022)$} \\
\hline Northeast & $17.8(182)$ \\
\hline Midwest & $19.7(201)$ \\
\hline South & $39.4(403)$ \\
\hline West & $23.1(236)$ \\
\hline \multicolumn{2}{|l|}{ Political Orientation $(n=1,018)$} \\
\hline Very conservative & $6.1(62)$ \\
\hline Conservative & $19.4(197)$ \\
\hline Moderate & $30.0(305)$ \\
\hline Liberal & $30.8(314)$ \\
\hline Very liberal & $13.8(140)$ \\
\hline
\end{tabular}




\section{Data Collection Procedure}

Prior to data collection, Institutional Review Board (IRB) approval was gained to ensure the ethical integrity of the research plan. The data for this study originated from voluntary and confidential electronic surveys collected through Amazon's Mechanical Turk (MTurk). MTurk is a crowdsourcing service that allows for a variety of different types of tasks to be posted and then completed by individuals who register with MTurk as "workers." Tasks are assigned reward values by the poster of the task, and a worker receives the reward upon successful completion of the task. Those who post tasks have the ability to examine completed work and refuse payment to the worker if the completed work is subpar (for example, if the majority of a survey was submitted unanswered). This method of data collection has become popular in the social sciences and has been utilized in several recent studies of crime and justice (Call, 2020; Lageson et al., 2019; Pogarsky et al., 2017; Struckman-Johnson et al., 2020). For the present study, a solicitation for U.S. residents at least 18 years of age to complete a survey was posted on MTurk for a reward of 25 cents. The solicitation linked potential respondents to the survey hosted on the web-based survey site SurveyMonkey. The solicitation for participants was posted on September 1, 2018. The survey was open for one week. Through a screening question, potential participants were asked if they currently work in the field of criminal justice. Respondents who indicated they were currently employed in the field of criminal justice were disqualified from the survey. As the purpose of the survey was to gauge the perceptions of the general public toward IBSA, the findings of the survey would be skewed by including those working in the field of criminal justice.

\section{Data Collection Instrument}

The data collection instrument was developed to measure the general public's experience with sexting and IBSA and attitudes toward IBSA. To gauge their experience with sexting and IBSA, all participants were asked if they had ever sent a photo or video to another individual that was intended to be sexually explicit. If answering affirmatively, the participant was asked a follow-up question about whether, to their knowledge, a sexually explicit photo or video of them they had consensually shared had ever then been shared without their consent. All participants were also asked if they had ever received a photo or video from another individual that was intended to be sexually explicit. If answering affirmatively, the participant was asked a follow-up question about whether they had ever shared a sexually explicit photo or video sent to them with a third party without the consent of the person in the photo or video.

Attitudes toward IBSA were measured using a series of five statements. Specifically, the instrument contained items addressing whether or not the recipient of sexually explicit photos or videos should share that material with others, if IBSA victims share any responsibility for their material being shared, the legality of IBSA in general, and the legality of IBSA in instances where the victim did not intend to share the material. Participants were asked to rate their level of agreement with each statement on a five-point Likert-type scale (strongly disagree $=1$, disagree $=2$, neither agree nor disagree $=3$, agree $=4$, strongly agree $=5$ ).

\section{Analytic Plan}

The data gathered from this research was examined using Statistical Package for the Social Sciences (SPSS), version 25. Frequencies were used to determine the participants' experiences with IBSA and their overall attitudes toward IBSA. Ordinary least squares (OLS) regression was conducted in order to examine the impact of multiple variables toward perceptions of IBSA. A review of the KolmogorovSmirnov Test and Q-Q plot suggests that the normality of the data was reasonable for OLS regression. Additionally, tests of the variance inflation factors (VIF) of predictors and the tolerance of predictor variables to see if the data met the assumption of collinearity indicated that multicollinearity was not a concern in any of the OLS analyses.

Seven independent variables were used in the multivariate analysis. Specifically, sex $(0=$ female; $1=$ male $)$, race $(0=$ white; $1=$ non-white), age (in years), education $(0=$ less than high school; $1=$ high school degree or equivalent; $2=$ some college, but no degree; 3 =associate degree; 4=bachelor's degree; 5=graduate or professional degree), parental status $(0=$ non-parent; $1=$ parent $)$, political orientation $(0=$ very conservative; 1=conservative; $2=$ moderate; $3=$ liberal; $4=$ =ery liberal), and sexting history $(0=$ never sent a photo or video to another individual that was intended to be sexually explicit; $1=$ have sent a photo or video to another individual that was intended to be sexually explicit) were included in the regression analyses.

\section{Results}

The experiences of the participants with sexting and IBSA are displayed in Table 2. Slightly more than one-third $(34.7 \%)$ of the respondents indicated that they had sent a photo or video to another party that was intended to be sexually explicit. These respondents were most likely to be female (59.4\%), white $(76.0 \%)$, in their thirties $(41.4 \%)$, hold a 
Bachelor's degree (35.9\%), be unmarried (55.49\%), almost equally likely to have children $(49.1 \%)$ or not have children $(50.9 \%)$, reside in the South $(41.24 \%)$, and identify as politically liberal (32.86\%). Of those who reported engaging in this behavior, one-fifth $(20.3 \%)$ of those respondents allege that, to the best of their knowledge, someone who they shared a sexually explicit photo or video with went on to share that material further without their consent. These respondents were most likely to be female $(55.6 \%)$, white $(81.9 \%)$, between the ages of 18 and $29(40.3 \%)$, hold a Bachelor's degree (37.5\%), almost equally likely to be married $(51.4 \%)$ or unmarried $(48.6 \%)$, have children $(57.1 \%)$, reside in the South $(45.8 \%)$, and be equally likely to identify as either politically conservative $(26.8 \%)$ or moderate $(26.8 \%)$. Receiving a sexually explicit photo or video was more common than sending a sexually explicit photo or video as slightly more than one-half (51.1\%) of the respondents indicated that they had received a photo or video from someone that was intended to be sexually explicit. These respondents were most likely to be female $(56.6 \%)$, white $(76.58 \%)$, in their thirties $(39.9 \%)$, hold a Bachelor's degree (35.9\%), be unmarried $(56.3 \%)$, equally likely to have children $(50.0 \%)$ or not have children $(50.0 \%)$, reside in the South $(42.7 \%)$, and identify as politically liberal $(32.3 \%)$. Of those respondents who reported receiving this material, $10.2 \%$ reported that they had shared this material with a third party without the consent of the individual who originally sent them the sexually explicit material. These respondents were most likely to be male $(58.5 \%)$, white $(79.3 \%)$, between the ages of 18 and 29 (39.6\%), hold a Bachelor's degree (52.8\%), be unmarried $(54.7 \%)$, have children $(54.9 \%)$, reside in the South (49.1\%), and identify as politically liberal (32.1\%).

The descriptive statistics pertaining to the perceptions of the sample toward IBSA-related issues are presented in Table 3 . The vast majority (91\%) of the respondents agreed or strongly agreed that if an individual receives sexually explicit photos or videos of someone, that individual should not share them without consent. The respondents were slightly less supportive, but still largely in favor of the criminalization of IBSA with $86.8 \%$ of respondents agreeing or strongly agreeing that sharing sexually explicit photos or videos of someone without their permission should be illegal. The public's support for criminalization differed when a distinction was made between whether the victim had originally and consensually shared the sexually explicit material with the perpetrator or not. More than one-third (36.7\%) of the respondents agreed or strongly agreed that the sharing of sexually explicit photos or videos of someone without their permission should be illegal only if the victim did not intend to share the material with anyone, such as if their mobile device or computer were hacked and the material stolen from them. Nearly half of the respondents attributed at least

Table 2: Sexting \& ISBA Experience

\begin{tabular}{|l|c|}
\hline $\begin{array}{l}\text { Have you ever sent a photo or video to another individual that was intended to be sexually explicit? } \\
(\boldsymbol{N}=\mathbf{1 , 0 2 3})\end{array}$ & \\
\hline No & $65.3(668)$ \\
\hline Yes & $34.7(355)$ \\
\hline & \\
\hline $\begin{array}{l}\text { If yes, to the best of your knowledge, has someone who you shared a sexually explicit photo or } \\
\text { video with, shared that material with another party without your consent? ( } \mathbf{N = 3 5 5 )}\end{array}$ & \\
\hline No & $79.7(283)$ \\
\hline Yes & $20.3(72)$ \\
\hline $\begin{array}{l}\text { Have you ever received a photo or video from another individual that was intended to be sexually } \\
\text { explicit? }(\boldsymbol{N}=\mathbf{1 , 0 2 1 )}\end{array}$ & \\
\hline No & $48.9(499)$ \\
\hline Yes & $51.1(522)$ \\
\hline & \\
\hline $\begin{array}{l}\text { If yes, have you ever shared a sexually explicit photo or video that was sent to you with a third } \\
\text { party without the consent of the person in the photo or video? }(\boldsymbol{N}=\mathbf{5 2 2})\end{array}$ & \\
\hline No & $89.8(469)$ \\
\hline Yes & $10.2(53)$ \\
\hline
\end{tabular}


some blame to IBSA victims for their victimization as $48 \%$ of the sample agreed or strongly agreed that if an individual receives sexually explicit photos or videos from someone and then shares the photos or videos without permission, the victim is at least partially responsible due to originally creating and sharing the sexually explicit material.

The results of the multivariate analysis for belief that an individual receiving sexually explicit photos or videos should not share that material without permission are provided in Table 4. A significant regression equation was found $\mathrm{F}(7,986)=10.89$, $p<.000$ ), with an adjusted R2 of .07. Sex, age, parental status, political orientation, and sexting history were significant predictors of agreement. Specifically, males $(\beta=-.25, p<.001)$ and parents $(\beta=-.38, p<.001)$ were less likely to agree that an individual receiving sexually explicit photos or videos should not share that material without permission whereas older respondents $(\beta=.01, p<.01)$, more politically liberal respondents $(\beta=.10, p<.001)$, and respondents who had previously sent a sexually explicit photo or video to someone $(\beta=.01, p<.05)$ were more likely to agree that an individual receiving sexually explicit photos or videos should not share that material without permission.

The results of the multivariate analysis for belief that sharing sexually explicit photos or videos of someone without their permission should be illegal are also presented in Table 4. A significant regression equation was found $\mathrm{F}(7,986)=11.38, p<.000)$, with an adjusted R2 of .07. Only sex and political orientation were significant predictors of agreement. Males $(\beta=-.42, p<.001)$ were less likely to agree that sharing sexually explicit photos or videos of someone without their permission should be illegal whereas more politically liberal respondents $(\beta=.09, p<.001)$ had a greater likelihood of agreeing that sharing sexually explicit photos or videos of someone without their permission should be illegal.

The results of the multivariate analysis for belief that sharing sexually explicit photos or videos of someone without their permission should be illegal only if the victim did not intend to share the photos or videos with anyone are displayed in Table 4. A significant regression equation was found $\mathrm{F}(7,984)$ $=5.99, p<.000)$, with an adjusted $\mathrm{R} 2$ of .03. Sex, race, and age were found to be significant predictors of agreement. Male respondents $(\beta=.27, p<.001)$ and non-white respondents $(\beta=.41, p<.001)$ were more likely to agree that sharing sexually explicit photos or videos of someone without their permission should be illegal only if the victim did not intend to share the photos or videos with anyone whereas older respondents $(\beta=-.01, p<.05)$ were less likely to agree that sharing sexually explicit photos or videos of someone without their permission should be illegal only if the victim did not intend to share the photos or videos with anyone. It should be noted that both parental status and political orientation were approaching statistical significance with parents $(\beta=$ $.15, p<.09)$ being more likely to agree and more politically liberal respondents $(\beta=-.07, p<.07)$ being less likely to agree that sharing sexually explicit photos or videos of someone without their permission should be illegal only if the victim did not intend to share the photos or videos with anyone.

The results of the multivariate analysis for belief that if an individual receives sexually explicit photos or videos from someone and shares the content

Table 3: Attitudes Toward IBSA

\begin{tabular}{|c|c|c|c|c|c|}
\hline & \multicolumn{5}{|c|}{$\%(N)$} \\
\hline & $S D$ & $D$ & $N$ & $S A$ & SD \\
\hline $\begin{array}{l}\text { If an individual receives sexually explicit photos or } \\
\text { videos from someone, that individual should not } \\
\text { share the photos or videos without permission. }\end{array}$ & $0.6(6)$ & $1.6(16)$ & $6.8(70)$ & $19.8(203)$ & $71.2(728)$ \\
\hline $\begin{array}{l}\text { Sharing sexually explicit photos or videos of } \\
\text { someone without their permission should be illegal. }\end{array}$ & $0.9(9)$ & $3.4(35)$ & $8.9(91)$ & $26.8(274)$ & $60.0(614)$ \\
\hline $\begin{array}{l}\text { Sharing sexually explicit photos or videos of } \\
\text { someone without their permission should be illegal } \\
\text { only if the victim did not intend to share the photos } \\
\text { or videos with anyone (such as if their mobile device } \\
\text { or computer were hacked). }\end{array}$ & $15.0(153)$ & $25.9(264)$ & $22.4(229)$ & $22.0(225)$ & $14.7(150)$ \\
\hline $\begin{array}{l}\text { If an individual receives sexually explicit photos or } \\
\text { videos from someone and shares the photos or } \\
\text { videos without permission, the victim is at least } \\
\text { partially responsible due to originally creating and } \\
\text { sharing the photos or videos. }\end{array}$ & $14.6(149)$ & $20.3(208)$ & $17.1(175)$ & $32.9(337)$ & $15.1(154)$ \\
\hline
\end{tabular}


without permission, the victim is at least partially responsible due to originally creating and sharing the content are presented in Table 4. A significant regression equation was found $\mathrm{F}(7,986)=21.69, p<$ .000 ), with an adjusted R2 of .13. Race, age, parental status, political orientation, and sexting history were all significant predictors of agreement. Specifically, non-white respondents $(\beta=.17, p<.05)$, older respondents $(\beta=.01, p<.001)$, and parents $(\beta=.19, p$ $<.05)$ were more likely to agree that if an individual receives sexually explicit photos or videos from with those expressed in the extant literature. An IBSA victimization rate of $7 \%$ was found among the respondents in the present study while previous studies of IBSA have placed victimization rates among U.S. adults between 4\% and 12.8\% (Branch et al., 2017; Eaton et al., 2017; Lenhart et al., 2016; Ruvalcaba \& Eaton, 2020). It should be noted that while 7\% of the overall sample reported IBSA victimization, when focusing solely on those respondents who had participated in sexting, the victimization rate was $20.3 \%$. Roughly 1 out of every 5 respondents who has

Table 4: OLS Regression of Public Attitudes Toward IBSA

\begin{tabular}{|c|c|c|c|c|c|c|c|c|}
\hline \multirow[b]{2}{*}{ Variable } & \multicolumn{2}{|c|}{$\begin{array}{l}\text { Should Not Share } \\
\text { Material Without } \\
\text { Consent }\end{array}$} & \multicolumn{2}{|c|}{$\begin{array}{l}\text { IBSA Should be } \\
\text { Criminal }\end{array}$} & \multicolumn{2}{|c|}{$\begin{array}{l}\text { IBSA Should be } \\
\text { Criminal Only if } \\
\text { Victim Did Not Intend } \\
\text { Any Sharing }\end{array}$} & \multicolumn{2}{|c|}{ Victim Responsibility } \\
\hline & $b(S E)$ & $\beta$ & $b(S E)$ & $\beta$ & $b(S E)$ & $\boldsymbol{\beta}$ & $b(S E)$ & $\beta$ \\
\hline Sex & $-.25(.05)$ & $-.17^{* * *}$ & $-.42(.05)$ & $-.24 * * *$ & $.27(.08)$ & $.10 * * *$ & $.14(.08)$ & .06 \\
\hline Race & $-.09(.05)$ & -.06 & $-.03(.06)$ & -.01 & $.41(.10)$ & $.14 * * *$ & .17(.09) & $.06^{*}$ \\
\hline Age & .01(.00) & $.09^{* *}$ & .00(.00) & .04 & $-.01(.00)$ & $-.07 *$ & $.01(.00)$ & $.10^{* *}$ \\
\hline Education & $-.02(.02)$ & -.03 & $-.01(.02)$ & -.01 & $-.01(.03)$ & -.01 & $-.03(.03)$ & -.03 \\
\hline Parental Status & $-.14(.05)$ & $-.09 * * *$ & $-.05(.06)$ & -.03 & .15(.09) & .06 & (19(.09) & $.07 *$ \\
\hline $\begin{array}{l}\text { Political } \\
\text { Orientation }\end{array}$ & $.10(.02)$ & $.16^{* * *}$ & .09(.02) & $.11^{* * *}$ & $-.07(.04)$ & -.06 & $-.32(.04)$ & $-.27^{* * *}$ \\
\hline Sexting History & $.10(.05)$ & $.06^{*}$ & $-.02(.06)$ & -.01 & $-.01(.09)$ & -.01 & $-.32(.08)$ & $-9.10 * * *$ \\
\hline Constant & $4.39(.12)$ & & $4.36(.13)$ & & $3.11(.21)$ & & $3.46(.20)$ & -3.75 \\
\hline
\end{tabular}

someone and shares the content without permission, the victim is at least partially responsible. Whereas more politically liberal respondents $(\beta=-.32, p<.001)$ and respondents who had previously sent a sexually explicit photo or video to someone $(\beta=-.32, p<.001)$ were less likely to agree that if an individual receives sexually explicit photos or videos from someone and shares the content without permission, the victim is at least partially responsible. It should be noted that sex was approaching statistical significance with male respondents $(\beta=.14, p<.07)$ being more likely to agree that victims bear at least some responsibility for their victimization.

\section{Discussion}

The present study examined the public's participation on sexting and IBSA while also examining their attitudes toward IBSA and the variables that influence those attitudes. The prevalence of IBSA victimization among the sample are in line sent a sexually explicit image or video to someone else has had that material shared further without their consent.

Fewer studies have examined the extent of IBSA perpetration, but the rate of IBSA perpetration ascertained from the sample of the present study is comparable to previous research. Among the respondents, $5.2 \%$ reported sharing sexually explicit material that was sent to them with a third party without the consent of the person in the material. A slightly higher rate of IBSA perpetration of $6.4 \%$ was found in an Australian study (Powell et al., 2019); however, Ruvalcaba and Eaton (2020) also found an IBSA perpetration rate of $5.2 \%$ in a national survey of U.S. residents.

The results of the present study indicate that a large majority of individuals believe that IBSA is inappropriate. This finding is in line with the available research on IBSA. For instance, $91 \%$ of respondents in the present study agreed that those who receive sexually explicit material from someone should not 
share that material with others without permission while Branch and colleagues (2017) found that over $92 \%$ of college students agreed that someone who receives a sexually explicit photo from someone should not share that photo without permission. Nearly $87 \%$ of the respondents in the present study also believe that IBSA should be illegal. This is slightly less than the $94 \%$ agreement with the criminalization of IBSA found by Lageson and colleagues (2019), but still, the vast majority of respondents find IBSA to be both inappropriate and criminal behavior.

Support for the criminalization of IBSA changes when specific forms of IBSA are introduced. While nearly $92 \%$ of the respondents in the present study agreed that sharing sexually explicit material of someone without their permission should be illegal, $36.7 \%$ agreed that sharing sexually explicit material of someone without their permission should be illegal only if the victim had not previously shared the material with anyone. Thus, more than one-third of the respondents only recognize certain victims of IBSA. The idea of certain IBSA victims being "better" victims can also be seen in the work of Lageson and colleagues (2019) who reported that $94.4 \%$ of their sample supported the criminalization of IBSA in general, but the level of support dropped to $76.3 \%$ when focusing specifically on the criminalization of IBSA that involved material originally created by the victim. In the study by Lageson and colleagues (2019), a victim who had sexually explicit material of them shared without permission but participated in the creation of the material was perceived as less of a victim than one who had sexually explicit material of them shared without consent but did not knowingly create the material.

Christie (1986) proposed the existence of an "ideal victim" who, be it an individual or group, is recognized completely as a victim following a criminal experience. To be awarded ideal victim status, the victim must possess certain attributes: (1) weakness, (2) being involved in a respectable act at the time of victimization, (3) being at a legitimate location, (4) victimized by an offender who is dangerous, and (5) the offender is an unknown presence. The IBSA victim who shares sexually explicit material of themselves with others before it is shared without their consent does not fit the characteristics of the ideal victim, and this may explain the lower levels of support for them. One of the ideal victim characteristics is involvement in a respectable act. Christie (1986) gives the example of a victim on her way home from caring for her sick sister. The IBSA victim who created and shared sexually explicit material of themselves is not being recognized as engaging in a respectable act; thus, it is easier to view this victim as non-ideal. Further, an ideal victim requires an ideal offender. According to Christie (1986), "the ideal offender differs from the victim.... He is a dangerous man coming from far away" (p. 26). The ideal offender is a visible threat and a stranger. The IBSA offender who non-consensually shares sexually explicit material sent to them by the victim does not fit this characterization. If the victim initially sent the offender sexually explicit material, perhaps even creating it specifically for them, it stands to reason that the victim did not view the perpetrator as dangerous and that the offender is an intimate partner or an intended intimate partner. With that in mind, members of the public may not view an IBSA offender as an ideal offender, which also alters the perception of the victim.

When discussing the concept of the ideal victim and IBSA, it is important not to overlook male IBSA victimization. Prior studies report that women are more likely to be victims of IBSA than men (Branch et al., 2017; Eaton et al., 2017; Ruvalcaba \& Eaton, 2020; Uhl et al., 2018). In the present study, the majority $(55.6 \%)$ of those who reported a belief that, to the best of their knowledge, someone who they shared a sexually explicit photo or video with went on to share that material further without their consent were female. Males made up $44.4 \%$ of those reporting the same belief. That is not an inconsequential minority. The male victim of IBSA is also not an ideal victim for the same reasons highlighted above and also because male victimization, particularly of a sexual nature, is incongruent with societal perceptions of masculinity.

The finding that over one-third of the public is only supportive of IBSA criminalization if the victim never shared the sexually explicit material in the first place leads to the larger issue of victim blaming. Christie's (1986) ideal victim is one who cannot be blamed for their victimization. As the IBSA victim does not meet the criteria for ideal victim status, the IBSA victim is, to some degree, blamed for being victimized. In the present study, nearly half (48\%) of the respondents agreed that IBSA victims are at least partly responsible if someone they consensually shared sexually explicit photos or videos with goes on to share those same photos or videos without their consent due to the victim originally creating and sharing the material. This level of victim blaming is higher than that found by Branch et al. (2017), where $18 \%$ of respondents agreed that a person consensually sharing sexually explicit photos of themselves deserves to have that material shared with others, but lower than the level of victim blaming found by Henry et al. (2017), where $65 \%$ of respondents agreed that a person who sends an intimate image to another person is at least partially responsible if that image is then shared with others. Much like victims of rape (Bieneck 
\& Krahe, 2011), intimate partner violence (Meyer, 2016), and online fraud (Cross, 2015), IBSA victims appear to be yet another group who are viewed as lessthan-credible victims.

While majorities of the sample agreed that IBSA is inappropriate and that IBSA should be illegal, the tendency toward victim blaming of those experiencing IBSA has dire implications. By feeling as if their victimization is their own fault, the negative mental health consequences of IBSA victimization may be exacerbated. Victims may also be less likely to come forward to report IBSA if they feel that their victimization will not be taken seriously. Blaming IBSA victims also minimizes the abusive behavior by placing the expression of one's own sexuality on the same level as non-consensually sharing the expression of another's sexuality. Much like if the rape victim had not exercised their sexuality by dressing in a way that emphasized their sexuality, if the IBSA victim had never taken a photo or video of themselves to begin with or had at least not shared it initially, then it could not have been shared without consent.

Multiple variables were found that significantly influenced perceptions of IBSA. It should be noted, however, that education level did not significantly influence perceptions of IBSA in any model. The influence of sex on the participant's attitudes toward IBSA reinforced the gendered nature of IBSA. In the present study, male respondents were significantly less likely than female respondents to agree that an individual receiving sexually explicit photos or videos should not share that material without permission and also significantly less likely to agree that sharing sexually explicit photos or videos of someone without their permission should be illegal. Additionally, male respondents were significantly more likely than female respondents to agree that sharing sexually explicit photos or videos of someone without their permission should be illegal only if the victim did not intend to share the photos or videos with anyone.

While male respondents seem to support the notion that only certain victims (i.e., those who did not intend to share sexually explicit material of themselves with anyone) are true victims of a crime, sex did not significantly influence the belief that an IBSA victim is at least partly responsible for their victimization due to originally creating and sharing the material. In fact, of all of the statistically significant variables, sex was the only variable that did not influence perceptions of victim responsibility. Race, age, parental status, political orientation, and sexting history all significantly influenced perceptions of victim responsibility. Specifically, non-white respondents, older respondents, respondents who are parents, politically conservative respondents, and respondents who had never participated in sexting were more likely to place blame on victims of IBSA. Of those variables, the only one previously examined in relation to victim blaming and IBSA in the extant literature is sexting history. Like the results of the present study, Scott and Gavin (2018) also found that those who had not previously participated in sexting were more likely to blame IBSA victims than those who had participated in sexting in the past.

The present study is not without limitations. Data for this study was generated from opt-in respondents using the crowdsourcing service MTurk. A reasonable set of concerns exists over the data provided by these opt-in respondents and the representativeness of the sample. Research has consistently indicated, however, that MTurk produces reliable data that does not significantly differ from data derived by more traditional methods and largely approximates the U.S. population (Buhrmester et al., 2011; Casler et al., 2013; Goodman et al., 2013; Ipeirotis, 2010). While there is nothing to substantiate concerns over the use of MTurk to gather the data, there still may be concerns over the quality of the responses. IBSA is an emerging social issue, and the respondents' perceptions of IBSA may have been shaped by recent media stories related to IBSA or influential cases in their areas prior to their participation in the study. Additionally, as IBSA is a sensitive issue, respondents may have felt the need to answer the survey questions in a socially acceptable manner, especially if they had ever engaged in IBSA. IBSA is also a complex issue, and the lack of a qualitative component for respondents to elaborate on their responses limits our understanding of their perceptions. Furthermore, several types of behavior can fall under the umbrella of IBSA. IBSA can involve the sharing of sexually explicit material received in confidence, the sharing of sexually explicit material stolen or hacked from technological devices, the sharing of secretly recorded material, the sharing of digitally altered or "deep fake" sexually explicit material, and other types of behavior. The present study explored the issue of IBSA in a general sense. Future research may wish to examine public perceptions of various forms or scenarios of IBSA. Future research may also wish to examine perceptions of specific IBSA policies. The majority of respondents were supportive of IBSA criminalization, and nearly every state has IBSA legislation, but that legislation varies in terms of necessary criteria for an act to be considered IBSA and sanctions for IBSA. The public may hold varying perceptions on appropriate sanctions for IBSA.

IBSA is a technology-facilitated sex offense that can cause substantial harm to the professional lives, personal lives, and mental health of victims. As 
the technology used for IBSA becomes more accessible and the act of sexting more socially acceptable, it stands to reason that the practice of IBSA will persist and possibly grow. While the present study has its limitations, it provides a step toward better understanding how IBSA is perceived by the American public. Although the public appears to disapprove of IBSA and support its criminalization, there is still an air of blame attributed to those who are victimized. As the issue of IBSA continues to evolve in society and in the legal system, greater attention must be focused on understanding how IBSA is

\section{References}

Adegoke, Y. (2019, November 6). Why do people keep blaming the female victims of revenge porn?

The Guardian. https:/www.theguardian.com/lifeandstyle/comm entisfree/2019/nov/06/why-do-people-keepblaming-the-female-victims-of-revenge-porn

Barmore, C. (2015). Criminalization in context: Involuntariness, obscenity, and the First Amendment. Stanford Law Review, 67, 447-478.

Bates, S. (2017). Revenge porn and mental health: A qualitative analysis of the mental health effects on revenge porn survivors. Feminist Criminology, 12(1), $22-42$. https://doi.org/10.1177/1557085116654565

Beyens, J., \& Lievens, E. (2016). A legal perspective on the non-consensual dissemination of sexual images: Identifying strengths and weaknesses of legislation in the US, UK and Belgium. International Journal of Law, Crime and Justice, 47 , 31-43. https://doi.org/10.1016/j.ijlcj.2016.07.001

Bieneck, S., \& Krahe, B. (2011) Blaming the victim and exonerating the perpetrator in cases of rape and robbery: Is there a double standard? Journal of Interpersonal Violence, 26(9), 1785-1797. https://doi.org/10.1177/0886260510372945

Bogage, J. (2019, October 26). Hidden camera footage of female college athletes posted to porn site, police say. The Washington Post. https:/www.washingtonpost.com/sports/2019/10 /24/hidden-camera-footage-female-collegeathletes-posted-porn-site-police-say perceived not just by the general public, but also by stakeholders in the criminal justice system in order to better address the harm caused by IBSA and the needs of victims.

Borrajo, E., Gámez-Guadix, M., \& Calvete, E. (2015). Cyber dating abuse: Prevalence, context and relationship with offline dating aggression. Psychological Reports: Relationships and Communications, 116(2), 565-585. https://doi.org/10.2466/21.16.PR0.116k22w4

Bothamley, S., \& Tully, R. J. (2018). Understanding revenge pornography: Public perceptions of revenge pornography and victim blaming. Journal of Aggression, Conflict, and Peace Research, 10(1), 1-10. https://doi.org/10.1108/JACPR-09-2016-0253

Branch, K., Hilinski-Rosick, C. M., Johnson, E., \& Solano, G. (2017). Revenge porn victimization of college students in the United States: An exploratory analysis. International Journal of Cyber Criminology, 11(1), 128-142. https://doi.org/10.5281/zenodo.495777

Buhrmester, M., Kwang, T., \& Gosling, S. D. (2011). Amazon's Mechanical Turk: A new source of inexpensive, yet high-quality, data? Perspectives on Psychological Science, 6(1), 3-5. https://doi.org/10.1177/1745691610393980

Call, C. (2020). The influence of victim type on the public's perceptions of sex offender registration and notification. Justice Policy Journal, 17(1), 122.

Casler, K., Bickel, L., \& Hackett, E. (2013). Separate but equal? A comparison of participants and data gathered via Amazon's MTurk, social media, and face-to-face behavioral testing. Computers in Human Behavior, 29(6), 2156-2160. https://doi.org/10.1016/j.chb.2013.05.009 
Christie, N. (1986) The ideal victim. In E. A. Fattah (Ed.), Crime policy to victim policy (pp. 17-30). St. Martin's Press.

Cross, C. (2015) No laughing matter: Blaming the victim of fraud. International Review of Victimology, 21(2), 187-204. https://doi.org/10.1177/0269758015571471

Cyber Civil Rights Initiative. (2021). 48 states $+D C$ + one territory now have revenge porn laws. https://www.cybercivilrights.org/revenge-pornlaws

Eaton, A. A., Jacobs, H., \& Ruvalcaba, Y. (2017). 2017 nationwide online study of nonconsensual porn victimization and perpetration: A summary report. Florida International University: Cyber Civil Rights Initiative. https://www.cybercivilrights.org/wp-content/uploads/2017/06/CCRI2017-Research-Report.pdf.

Goodman, J. K., Cryder, C. E., \& Cheema, A. (2013). Data collection in a flat world: The strengths and weakness of Mechanical Turk samples. Journal of Behavioral Decision Making, 26(3), 213-224. https://doi.org/10.1002/bdm.1753

Grant, M. (2014, September 1). Hundreds of intimate celebrity pictures leaked online following alleged iCloud breach. Newsweek. https://www.newsweek.com/hundreds-intimatecelebrity-pictures-leaked-online-followingsuspected-icloud-267851

Hall, M., \& Hearn, J. (2017). Revenge pornography and manhood acts: A discourse analysis of perpetrator's accounts. Journal of Gender Studies, 28(2), 158-170. https://doi.org/10.1080/09589236.2017.1417117

Henry, N., Powell, A., \& Flynn, A. (2017). Not just "revenge pornography": Australians" experiences of image-based abuse. A summary report. Melbourne: RMIT University. https://www.rmit.edu.au/content/dam/rmit/docu ments/college-of-design-and-socialcontext/schools/global-urban-and-socialstudies/revenge_porn_report_2017.pdf

Ipeirotis, P. G. (2010). Analyzing the Amazon Mechanical Turk marketplace. Crossroads, the ACM Magazine for Students, 17(2), 16-21.

Kamal, M. \& Newman, W. J. (2016). Revenge pornography: Mental health implications and related legislation. Journal of the American Academy of Psychiatry and the Law, 44(3), 359367.
Lageson, S. E., McElrath, S., \& Palmer, K. E. (2019). Gendered public support for criminalizing "revenge porn". Feminist Criminology, 14(5), 560-583.

https://doi.org/10.1177/1557085118773398

Lee, M. Y. H. (2019, October 22). California Rep. Katie Hill (D) denies affair with staffer and calls accusations of sexual impropriety a "smear." The Washington Post. https://www.washingtonpost.com/politics/califor nia-rep-katie-hill-d-calls-accusations-of-sexualimpropriety-a-smear/2019/10/22/41c4c2b2-f4e511e9-a285-882a8e386a96_story.html

Lenhart, A., Ybarra, M., \& Price-Feeney, M. (2016). Nonconsensual image sharing: One in 25 Americans has been a victim of "revenge porn." Data \& Society Research Institute, Center for Innovative Public Health Research. https://datasociety.net/pubs/oh/Nonconsensual_I mage_Sharing_2016.pdf

Mckinlay, T. \& Lavis, T. (2020). Why did she send it in the first place? Victim blame in the context of "revenge porn." Psychiatry, Psychology, and Law, 27(3), 386-396. https://doi.org/10.1080/13218719.2020.1734977

Meyer, S. (2016). Still blaming the victim of intimate partner violence? Women's narratives of victim desistance and redemption when seeking support. Theoretical Criminology, 20(1), 75-90. https://doi.org/10.1177/1362480615585399

Pogarsky, G., Roche, S. P., \& Pickett, J. (2017). Heuristics and biases, rational choice, and sanction perceptions. Criminology, 55(1), 85111. https://doi.org/10.1111/1745-9125.12129

Powell, A., Henry, N., Flynn, A., \& Scott, A. J. (2019). Image-based sexual abuse: The extent, nature, and predictors of perpetration in a community sample of Australian residents. Computers in Human Behavior, 92, 381-392. https://doi.org/10.1016/j.chb.2018.11.009

Ruvalcaba, Y., \& Eaton, A. A. (2020). Nonconsensual pornography among U.S. adults: A sexual scripts framework on victimization, perpetration, and health correlates for women and men. Psychology of Violence, 10(1), 68-78. https://doi.org/10.1037/vio0000233

Scott, A. J., \& Gavin, J. (2018). Revenge pornography: The influence of perpetrator-victim sex, observer sex and observer sexting experience on perceptions of seriousness and responsibility. Journal of Criminal Psychology, 8(2), 162-72. https://doi.org/10.1108/JCP-05-2017-0024 
Starr, T. S. \& Lavis, T. (2018). Perceptions of revenge pornography and victim blame. International Journal of Cyber Criminology, 12(2), 427-438. https://doi.org/10.5281/zenodo.3366179

Stroud, S. R. (2014). The dark side of the online self: A pragmatist critique of the growing plague of revenge porn. Journal of Mass Media Ethics, 29(3),

168-183. https://doi.org/10.1080/08900523.2014.917976

Struckman-Johnson, C., Anderson, P. B., \& Smeaton, G. (2020). Predictors of female sexual aggression among a U.S. MTurk sample: The protective role of sexual assertiveness. Journal of Contemporary Criminal Justice, 36(4), 499-519. https://doi.org/10.1177/1043986220936100

Uhl, C. A., Rhyner, K. J., Terrance, C. A., \& Lugo, N. R. (2018). An examination of nonconsensual pornography websites. Feminism \& Psychology, $28(1)$, https://doi.org/10.1177/0959353517720225
Xiong, C. (2020, December 30). Minnesota Supreme Court: "Revenge porn" not protected free speech. Star Tribune. https://www.startribune.com/minnesotasupreme-court-revenge-porn-not-protected-freespeech/600005240/?refresh=true

\section{About the Author}

Corey Call received his Ph.D. in public policy and administration from Virginia Commonwealth University. He is currently an assistant professor in the Department of Sociology, Anthropology, and Criminal Justice Studies at Longwood University. His primary research interests concern sex offending, sex offender management policies, serial murder, and media portrayals of criminal justice. 